की

UCID- 19605

acra- -19605

PROGRESS REPORT

September-0ctober 1982

Coating Processes Group

ง. N. Dini

ง. G. Romo

November 19, 1982

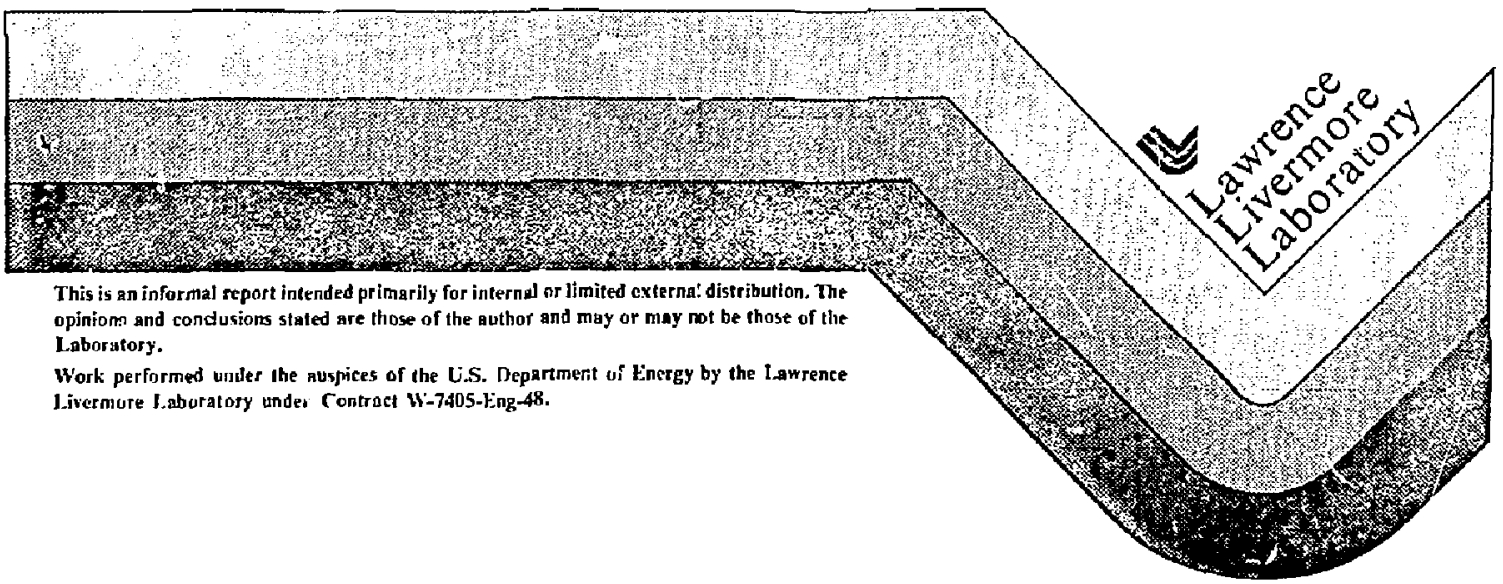




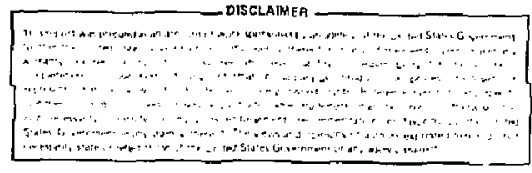

November 15, 1982

JWD-82-402

TO: Distribution

FROM: J. W. Dini/J. G. Ramo

SUBJECT: Progress Report - September-0ctober 1982

Coating Processes Group

SUMMARY OF CONTENTS

Pays No.

Technical Highlights

Weapons Program

W-84 Ion Plating at $Y-12-A$. Copeland

W-84 Ion Plating at VPL - A. Copeland

W-84 Solid State Bonding - A. Coneland

Nuclear Test Program

Diamond Ace - J. Karcher

Tome Event $=\mathrm{C}$. Holm

$X$-Ray Detector Cathodes for Cabra - C. Bruns

$X$-Ray Detector Foils for Cabra LOS-9 - C. Hawkes

Aluminum on Parylene for Cabra Filters - G. Hattery

Copper on Parylene Backed Magnesium - G. Hattery

Target Foils for Cabra LOS-8 - G. Hattery

Target Foils for Cabra LOS-8 - B. Junk

Crowdie - C. S. Brooks

Pinex Pinhole Development - Z. Briggs

Laser Pragram

Electropolishing Nova Spatial Filters - H. Patton

MFD Program

RTNS-II - C. M. Logan

Misce 11 aneous

ME Research - Solid State Bonding Using Electroplating - W. Feng LOOTM - Alpha Claddings - S. Patterson

Salvaging of Precious Metais - J. Loy

Nafion Cell Electrode Coating - G. Haugen

Thermocouple Holder Braze - R. Kudo

$X$-Ray Mirror Coatings - G. Sanger

NASA $X-R$ ay Mirrors - $G$. Sanger

Micro-Cnannel Plate Camera - 0 . Frice

Laser Flash Tube Failure - K. Whitham

Miscellaneous Non-Routine Vacuum Processes Jobs

Presentations

Publications
2

2

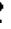 \\ 2}

3

3

3

4

4

4

4

5

5

5

5

5

6

6

7

7

8

8

8

8

9

9

9

10

\footnotetext{
$\because A+A$ a

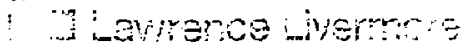

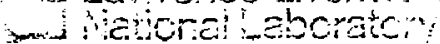


JWD-82-40?

November 15,1982

Page 2

\section{Tecnnical Highlights}

Weapons Program -- We are continuing to support the aluminum ion plating eftort for the $W-84$ both at $Y-12$ and in-house.

Diamond Ace and Cabra -- Heavy support from $V P L$ botn in vacuum engineering activities and fabrication of foils.

Laser Program -- Electropolishing of spatial filters for Noya is on schedule. ME Research -- This completed program showed that sound solid state joints can be odtained with silver electroplated on a variety of metals.

\section{WEAPONS PROGRAM}

\section{H-84 Ion Plating at $Y-12$ - A. Copeland}

We have helped $Y-12$ complete the process development portion of providing aluminum protective coatings on the W-84 parts. Basically, conventicnal ion-plating was tailored to suit the unique geometries and material constraints of the assembly. Tests being performed on mock assembljes are showing that the ion-plated aluminum coatings are providing the required protection. Permeability is noi detectable, thicknesses are well witnin tolerance (200 to 1000 microinches), and adherence is quite acceptable. Additional permeability tests are in progress. The next phase of this project is to transfer the process from the $Y-12$ Developtient Division to the $Y-12$ Production Division.

W-34 Ian-Plating at VPL - A. Copeland

In parallel with helping $Y-12$ satisfy immediate coating needs, we have started a project to develop a more controllable coating process, Our plan is to ion-plate using Magnetron sources instead of conventional resistance heated filament sources. This project has been addressed at a much lower priority level than the immeriate $Y-12$ needs. The hardware is 50\% complete and the initial run: are tentatively scheduled for early December 1982.

W-84 Solid State Bonding - A. Copeland

We have electrodeposited silver on 24 test specimens of various metals utilizing procedures developed on our recently completed ME Research Program on solid state bonding. Bob Rosen will have these units welded into containment cans for autoclave solid state bonding and will then test them to failure. 
JWD-82-40\%

November 15, 1982

Page 3

\section{Nuc lear Test Program}

Diamond ACE - J. Karcher

The full time support of the Diamond Ace experiment vacuum systems was concluded in September.

Due to leakage in the vaculm system, the pressure at shot time was on the order of 50 to 60 microns ( 5 to $6 \times 10^{-2}$ Torr) well above the design pressures of $10^{-6}$ Torr which were proven in July and August.

Even at the higher pressures, some 80\% of the experimental data was recuvered and the event is considered a successful physics experiment.

Companent tests are being conducted in order to determine possible failure modes which may have not been caught in previous testing. Part time support of this wark is expected to continue through mid December.

Tomme Event - C. Holm

Design work has begun on another tunnel shot similar to the Diamond Ace event. The experiment has a scheduled FOR in August 1983.

Direct support of the Nliriear Test Engineering Division (NTED) for the necessary vacuum engineering will come from VPL in conjunction with support from EG\&G, San Ramon. A requirement for full-time support is expectes to extend from January ' 83 through the balance of the shot.

X-Ray Detector Catnodes for Cabra - C. Bruns

We evaparated sesium jodjde (LSI) an aluminum X-ray detector cathodes. The side requiring the CsI coating was diamond machined, making handling inore difficult. The CsI coating had to be kept protected from moisture. CsI absorbs moisture quickly and the coating breaks down witnin minutes of exposure to room air. We installed a glove bag enclosing the vacuum system and kept it filled with argon under positive pressure. The shipping container was also inside the argon-filled bag. Parts and the vacuum system were therefore constantly kept in a dry argon environment. We recomnend that holding fixtures and all related parts that are to be used in such an environment be made with the consideration that manipulation is difficu?t when gloves must be used under positive pressure. The glove bag technique improved our ability to handle parts requiring a moisture-free environment. 
JW0-82-402

November 15, 1982

Paọe 4

X-Ray Detector Foils for Cabra LOS-9 - C. Hawkes

He coated Parylene and Formvar foils on both sides with a nucleating layer of copper and then zinc as an overcoat. The foils had to be pinnole free. The zinc would not adhere without a copper nucleating layer. This meant that four complete coater cycles (one each for copper and zinc and this rapeated for each side) and two different vacuum systems would be required to produce a part. We devised a set-up and switched to a multi-source vacuum system in which an electron beam gun was used. This allowed both copper and $z$ inc to be deposited in one coater cycle, in the same coater, cutting down coating time considerably. Techniques for evaporating zinc on fragile Parylene and Formvar foils were improved. More data on the diffusion of copper into zinc under these conditions needs to.be gathered.

Aluriinum on Parylene for Cabra Filters - G. Hattery

We deposited aluminum onto Parylene by electron bean evaporation. The fails were attacied to holders for use as filters for Cabra. One criteria for the foils was that they be pinhole free after coating. We took elaborate steps to try ta eliminate pinholes. One technique that helped was depositing half the coating on each side of the foils. This techrique, together with olowing of $f$ the foils lightly with deionized air just prior to closing the coating chamber succeeded in limiting, but not completely eliminating, the pinholes. The foils did satisfy the requestors needs.

Copper on Parylene Backed Magnesium - G. Hattery

We deposited copper onto existing Parylene Dacked magnesium foils by electron deam gun evaporation. The purpose of the copper was to cover pinhole defects in the foils so that they could be utilized in the Cabra shot. The foils had been fabricated by an outside vendor (Lebow) but fajled to meet specified light-tight requirements. The copper deposition did nat plug the pinhales through both the magnesium and the Parylene. Pinholes through the magnesium, but not the Parylene, were sealed. Therefore, there was an improvement, but not enough to meet the requirements. A clean room environment is necessary to reliabiy fabricate pinhole froe coatings and foils.

Target Foils for Cabra LOS-8 - G. Hattery

We coated Parylene foils on both sides with zinc on a nucleating layer of copper. These parts replaced foils that had used aluminum as a nucleating layer and had delaminated. The foils had to be pinhole free. We experienced no delamination. The foils did tend to become loose (i.e., not taut) during the coating process. Coating rate changes affected the foil tautness, but no taut foils were produced using the electron beam gun. We produced taut foils using a resistance heated source, but the only available system could only evaporate one type of material witnout time consuming adjustments oetween runs. It was therefore not used to produce the parts. The foils produced by electron beam gun were accepted for the application. 
JWD $-82-402$

November 15,1982

Page 5

Target Foils for Cabra LOS-8 - B. Junk

We evaporated zinc on a nucleating layer of aluminum, which was evaporated ento Parylene foils. The foils had to be pinhole free. We therefore evaporated zinc on both sides of the Parylene so that any pinholes in the zinc coatings would be offset. We had coated Parylene with $z$ inc using a copper nucleating layer and expected the aluminum to behave similarly. There was no apparent difference until after the finished parts were delivered. The parts then delaminated. Further tests comparing the nucleation of $z$ inc on copper with zinc on aluminum indicated that nucleation of zinc on aluminum was very poor, compared to copper. Coatings of zinc on aluminum may be practica] in thicknesses greater than $700 \mathrm{~nm}$.

Crowdie - C. S. Brooks

Electroformed parts requiring three different coatings are required by January 2. These parts are especially challenging since they require thicker coatings than we've ever done and a deposit which we have never produced to this requirement. The ijirst stage $\approx i$ the electroforming process has now been completed.

Pinex Finhole Development - Z. Briggs

We have produced 11 pinnoles for Branco with $2 \mathrm{mil}$ and 4 mil diameter noles by 1 inch long and are currently electroforming 8 units in the 6 and 8 mil size. our next challenge is to produce $1 / 2 \mathrm{mi}$ diameter pinholes that are one-half inch long.

\section{Laser Program}

Electropolishing Nova Spatial Filters - H. Patton

The total number of spatial filters that need to be electropolished include 72 for Nova and 18 for the two beam lines tnat wi i i be assemb led in France. We have finished 18 of these parts and estimate that it will take until February 1983 to finish the remainder.

\section{MFD Program}

RTNS-I I - C. M. Logan

Because of oxidation of the tritide on several $23 \mathrm{~cm}$ targets, there was a need to process via the wax electroforming method 20 new targets on a short time frame schedule. This was done and some of these targets are already at $y-12$ for tritide loading.

A proposal which suggests various electrodeposition schemes for providing a Substrate material capable of meeting the property requirements of RTNS-II (e.g., a yield strength of at least $50,000 \mathrm{psi}$ after 4 hours at $400 \mathrm{C}$ and an electrical conductivity of at least $80 \%$ that of pure copper) has been funded by the RTWS program. Three approaches will be evaluated: (1) electrodeposition of a dispersion hardened copper, (2) electrodeposition of hard copper pyrophosptrate, anu' $\{\hat{s}\}$ electrodeposition of copper al lays. We are just beginning to start working on this program. 
JWD-82-402

November 15, 1982

Page 6

Miscellaneous

ME Research - Solid State Bonding Using Electroplating - W. Feng

Stainless stee] and some other metals were so? id state bonded with the aid of electroplated silver. Sound, stroilg joints were obtained with $1 / 2$ inch diameter cylindrical butt specimens under a variety of bonding conditions. The procedures used for preparing the substrates for plating were first characterized by using ring shear tests which provided quantitative information on bond adhesion. For the bonding studies, a full factorial experiment with two levels and four variables $\left(2^{4}\right)$ was run with stainless steel. The four variables included in the study were: time (1 $\mathrm{nr}$. and 4 $\mathrm{hr}$.$) , temperature (300C and 600C), bonding pressure (10,000 \mathrm{ps} i$ and 30,000 psi), and silver plating thickness ( $1 \mathrm{mi}$ and $6 \mathrm{mil})$. With stainless steel, the mean bond strength was 47,800 ps $i$ with failure occurring within the silver electrodeposit. Time was a non-significant variable, while thickness, pressure and temperature were all significant as were the interactions of temperature with pressure and temperature with thickness. Although full factorial experiments were not run with other materials, enougin data were obtained to reveal that time was insignificant for these materials, temperature was very significant and thickness and load relatively insignificant. A final report has been written on this project and is presently going through the approval process.

LOUTM - Alpha Claddings - S. Patterson

A. Hard Copper

We are investigating deposition of a hard copper deposit for the Alpha program. The goal is to produce a deposit that will be hard and yet not change properties, e.g., lose hardness and strength as a function of time. Preliminary work with a pyrophosphate copper solution containing a proprietary addition agent $(P \gamma-6 l-H)$ has shown promising results. Data presented in Table 1 show that deposits produced in solutions containing $500 \%$ and greater than vendor recommended amounts of the additive were stronger and retained their strength even after exposure to $250 \mathrm{C}$ for 4 hours.

B. Plating on Molybdenum

Two procedures for plating on molybdenum irere evaluated:

1. Bell Labs Process - the key steps in this method include two firing cperations in dry hydrogen at $1000 \mathrm{C}$.

2. Hughes Aircraft Process - the key steps in this method include a multitude of firing steps at $800 \mathrm{C}$. 
JWD-82-402

November 15, 1982

Page 7

Ring shear tests were used to obtain quantitative data for gold plated on molybdenum which was treated by the above procedures. Results showed consistently higher values for the specimens prepared via the Bell Labs method, e.g., bond strengths of 18,000 psi were consistently obtained and failure occurred entirely within the gold deposit. Specimens treated by the Hughes Aircraft process exhibited an average fajlure of 11,500 psi witn failure often invoiving separation at the molybdenum-gold interface.

Table 1

Ultimate Tensile Strength of Pyrophosphate Copper as a function of Brighter Concentration

Brightener $\frac{\text { Concentration* }(\%)}{0}$

100

200

300

400

500

750

1000
Tensile Strengtn ( $K$ psi)

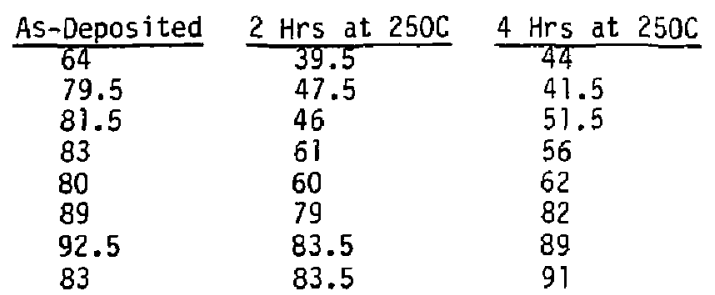

*PY-61-H, M\&T Corp., Rahway, NJ

\section{Miscellaneous}

Salvaging of Precious Metals - J. Loy

Over the past five years or so, Materials Management has built up a backlog of precious metal plated parts that are scrap. These include printed circuit boards, reflectors, targets and a variety of other parts. We salvage the precious metal coatings on these parts, and to date this year have recovered 60 troy ounces of gold.

\section{Nafion CeII Electrode Coating - G. Haugen}

We electron beam evaporated gold onto both sides of two nickel electrodes. The Nafion is sandwiched between the two electrodes to maintain contact during the swelling which occurs due to the Nafion absorbing water. The initial request was for us to deposit nickel through a grid pattern directly onto Nafion. During the requester's experiment, the nickel coating would peel of $f$ due to the distortion caused by the Nafion absorbing water. Using the goid coated nickel electrodes eliminated the problem of losing constant current flow to the Nafion which is used to electrolyze water into hydrogen and oxygen. 
JWD-82-402

November 15, 1982

Page 8

Thermocouple Holder Braze - R. Kudo

We were asked to vacuum braze a stainless steel cap to the end of an electrolytic tough pitch (ETP) copper tube for use as a thermocouple nolder. ETP copper is not desirable for vacuum brazing because it is difficult to reliably achieve leak tight joints. Another special consideration was that we were requested to use a braze alloy that did not contain nicke?. Tnis forced us to use a less desirable alloy, Silcoro 75, which resulted in a vacuum leak at the joint. Numerous attempts to seal the leak by remelting the alloy failed. As a last resort we used Cusil, a lawer temperature alloy, and succeeded in plugging the leak. Cusil is not normaily used to braze to SST without first nickel plating. However, in this case it was able to wet to the Silcoro 75 and close the leak.

X-Ray Mirror Coatings - G. Sanger

In conjunction with Optics we are developing a coating process to produce $x$-ray mirrors consisting of very thin alternating-layers of two dissimilar metals on glass substrates. Initially we have produced three specimens, by Magnetron sputtering, each having a total of 101 layers. The tinickness of each layer is $3 \mathrm{~nm}$ on one specimen, $1.5 \mathrm{~nm}$ on another specimen, and only 0.5 nm (5A) on another. The Optics Group will be evaluating the results. A shutter mechanism was devised to precisely meter the deposition intervals. The EE Machine Control Group produced a controller that provides intervals of one-to-99 seconds and a repetition rate of one-to-999 seconds. The use of two (50 $\mathrm{mm}$ diameter) Magnetron guns instead of two electron-deam guns has resulted in a sudstantial savings of both time and money.

NASA X-Ray Mirrors - G. Sanger

We were asked to deposit adherent coatings of copper, with a chrome interface, on quartz parts for the subsequent fabrication of $x$-ray mirrows. The coatings serve as a base for electroplating a 3 mil thick coating of copper which is then diamond turned to a mirror finish. For best adhesion, the parts were heated to $300^{\circ} \mathrm{C}$ during the PVD process. We saved time by fabricating a special fixture that permitted coating up to three parts each run.

Micro-Channel Plate Camera - D. Price

We have developed a technique for joining $\mathrm{Al}_{2} \mathrm{O}_{3}$ to a piece of $\mathrm{SnO}_{2}$ coated fiber optics giass. A test braze was completed to prove the feasibility of making such a joint for the fabrication of a micro-channel plate camera. The problem was to create a good joint between two ceranjc materials at a low enough temperature to not break the glass. The braze alloy Eutectic 157 was chosen because of its low melting temperature of approximately $260^{\circ} \mathrm{C}$. Initial tests showed that of the materials considered for an interface, this alloy would wet copper best. Both test pieces were vapor plated by the requestor with a $20 \mathrm{~lm}$ base layer of chrome (to promote adhesion) and a $200 \mathrm{~nm}$ layer of copper. The braze appears to have worked well, with braze alloy wetting both surfaces. The joint is currently being tested for vacuum tightness. 
JWD-82-402

November 15, 1982

Page 9

Laser Flash Tube Failure - K. Whitham

We were asked to assist in (1) determining the reason for failures in laser flash lamps, and (2) recommending a remedy. The commercially made lamps have been failing at various stages of their life by developing breaks at the tungsten to glass seal. At a meeting, involving the requestors, members of VPL and the glass lab, we offered some ideas that we feal snould reduce the breakage problem substantially. The ideas involved modifying the lamps, This would be desirable because a large number of the lamps already exist.

Miscellaneous Non-Routine Vacuum Proresses Jobs

Tested contents of Jiamond-fice gas salmp ie botties - v'. Gregory.

Induction and radiant heat brazed streak camera components - J. Bushman.

Evaporated boron foils for Caora LOS-9 - G. Hattery

Determined outgassing characteristics of RF gasket - J. Karcher.

Tested Diamond-Ace vacuum gauges - J. Kroger

Provided SEM vacuum system maintenance - C. Witherel\}.

Determined outgassing characteristics of epoxy coated aluminum - J. Karcher. Furnace tested CRI-012 part - C. Brooks.

Induction brazed Advac to SST fittings - C. Gillium.

\section{Presentations}

1. W. K. Kelley, W. C. Cowden, and G. E. Overturf, "Electroforming Cylindrical Parts with Precision Snall Inside Diameter Pinholes", ICMDC/SUBJOG-12A, September, Rocky Flats.

2. W. K. Kelley, "Use of Electrodeposition to Provide Coatings for Solid State Bonding", same meeting as 1 above,

3. T. 8. Beat, S. E. Sriggs, "Quartitative Adhes ion data for Tho Energetic PVO Processes", Same meeting as 1 above.

4. T. G. Beat, J. G. Romo, G. Griggs, D. Berger, R. Reiss, and T. Brown, "Fabrication of Foils for Caboc", same meeting as 1 above.

5. J. G. Rittmann, "LLNL/Materials Fabrication Division Specialty Facilities/Coatings Overview" same meeting as I above.

6. W. K. Kelley, G. E. Overturf, J. W. Dini and D. P. Atkinson, "Joining a Large Brass Ring to Stainless Steel with the Aid of Electroplating", Electrochemical Society 1-62 Meeting, Detroit, Mich., Oct.

7. J. W. Dini and H. R. Johnson, "Plating on Titanium and Zirconium", ASTM Conference on Titanium and Zirconium in Industrial Applications, New Orleans, Sept. 21, 1982. 
JWD $-82-402$

November 15, 1982

Page 10

8. J. W. Dini, "Influence of Impurities on the Properties of Nickel Electrodeposits", Seattle Branch, American Electroplaters' Society, Oct. $1 \mathrm{~s}, 1982$.

9. J. W. Dini, "Plating on Difficult to Plate Metals", Partland Branch, American Electroplaters' Society, Oct. 14, 1982.

\section{Publications}

3. D. D. Berger, "Calcium Flouride Window Mounting", Review of Scjentific Instruments, 53 (10), 1619 (1982).

2. J. W. Dini, "Electrodeposition - A Viable Coating Alternative", Thin Solid Fjims, 95, 123-129 (1982).

3. J. W. Dini and H. R. Johnson, "Plating on Titanium and Zirconium", UCRL-87।I1, Sept. 1982 .

4. J. W. Dini, F. B. Waldrop and R. W. Reno, "Surface Preparation and Plating", UCRL-88199, Oct. 1982.
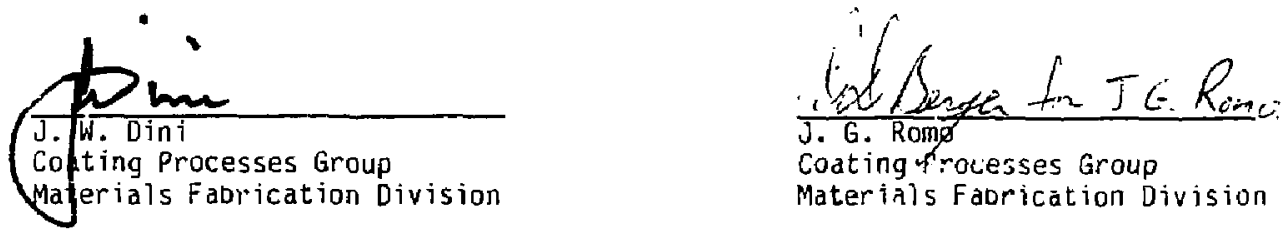

JWD: JGR: Jm

$1956 R$ 